\title{
A novel phospholipid-binding protein from the yeast Saccharomyces cerevisiae with dual binding specificities for the transport GTPase Ypt7p and the Sec 1-related Vps33p
}

\author{
Thomas Lazar ${ }^{\mathrm{a}}$, Dietrich Scheglmann ${ }^{2) \mathrm{b}}$, Dieter Gallwitz ${ }^{1) \mathrm{a}}$ \\ a Department of Molecular Genetics, Max Planck Institute for Biophysical Chemistry, Göttingen/Germany \\ b Institute of Biochemistry II, Medical Faculty, University of Jena, Jena/Germany
}

Received September 20, 2002

Accepted September 28, 2002

membrane fusion - vacuole - intracellular transport organelle biogenesis - multivesicular bodies

The gene product of the Saccharomyces cerevisiae open reading frame $Y D R 229 w$ (named IVYI for: Interacting with $V$ ps33p and Ypt7p) was found to interact with both the GTPase Ypt7p and the Sec1-related Vps33 protein. While deletion of IVY1 does not lead to any recognized change in phenotype, overexpression of Ivy1p leads to fragmentation of the vacuole, missorting of the vacuolar enzyme carboxypeptidase Y (CPY) to the exterior of the cell, and an accumulation of multivesicular bodies inside the cell. All effects caused by the overexpression of Ivy1p can be reset by simultaneously raising the amount of Vps33p. This suppression activity of Vps33p suggests that Ivy1p and Vps33p at least partially counteract the action of each other in the cell. The intracellular level of Ivy1p increases in cells approaching stationary growth phase at which part of the protein is located at the rim of the vacuole. In addition to its specific interactions with members of two regulatory protein families, Ivy1p in vitro shows a marked propensity for binding phospholipids with high affinity.

\section{Introduction}

Studies in vitro and in vivo of yeast vacuole membrane fusion have added a great deal to our understanding of $\mathrm{Ypt} / \mathrm{Rab}$ GTPase-controlled, SNARE-mediated membrane fusion events in eukaryotic cells (reviewed in (Götte and Lazar, 1999; Wickner, 2002)). During the so-called docking step of the

1) Professor Dr. Dieter Gallwitz, Department of Molecular Genetics, Max Planck Institute for Biophysical Chemistry, Am Fassberg, D-37070 Göttingen/Germany, e-mail: Dieter.Gallwitz@mpi-bpc.mpg.de, Fax: +495512011718

2) Present address: biolitec AG, Winzerlaer Strasse 2a, D-07745 Jena/ Germany fusion event the syntaxin-like vacuolar SNARE Vam3p binds the regulatory Vps33 protein which is part of a large multisubunit protein complex (Sato et al., 2000). This heterogeneous supramolecular aggregate is variously known as HOPS (Seals et al., 2000) or the Vps C complex (Sato et al., 2000). Vps33p is a member of the Sec1 protein family. It shuttles between a membrane-bound and a soluble state (Gerhardt et al., 1998). During the docking step, the HOPS/Vps C protein complex is transferred to the regulatory GTPase Ypt7p (Price et al., 2000). Ypt7p belongs to the highly conserved 11-member family of $\mathrm{Ypt} / \mathrm{Rab}$ GTPases that are involved in the regulation of membrane recognition/docking processes (Lazar et al., 1997). Each of these GTPases is supposed to perform a similar function at a specific transport step. Ypt7p is required to be present on both membranes determined to fuse with each other. In agreement with its role during vacuolar membrane docking, the membrane-bound fraction of the cellular pool of Ypt7p has been localized to the vacuolar membrane (Haas et al., 1995). A component of the HOPS/Vps C complex, Vps39p (also known as Vam6p), directly interacts with Ypt7p and drives the exchange of GDP for GTP, thereby helping switch the GTPase from the inactive to the active state (Wurmser et al., 2000). $\mathrm{Vps} 39 \mathrm{p}$ is therefore thought to be the guanine nucleotide exchange factor (GEF) for Ypt7p. Downstream of Ypt7p, two additional monomeric GTPases, Rho1p and Cdc42p (Müller et al., 2001; Eitzen et al., 2001) help regulate vacuoles to dock to each other. The docking step with its multitude of protein factors most likely serves as an identification/proofreading step during the sequence of events from priming to fusion. During the docking process, Ypt7p interacts with Ccz1p, a protein known to be involved in the detoxification of metal ions by the vacuole (Kucharczyk et al., 2001). Details of the molecular events downstream of Ypt7p are summarized in (Mayer, 2001).

By searching for new interaction partners for the GTPase Ypt7p with a two-hybrid system library screen, we have discovered Ydr229w (named Ivy1p), an as yet undescribed 
binding partner for Ypt7p. Ivy1p represents a novel class of proteins which were not known to interact with Ras-related transport GTPases. Next to Ypt7p, Ivy1p binds the Sec1-related Vps33p and various phospholipids. To our knowledge, Vac1p is the only yeast protein with a similar set of interactions that has been described to date (Tall et al., 1999). Certain phospholipids have been recognized to fulfill not only structural functions as membrane components but to exert effects as membranelocated sensor molecules or/and signal mediators (Hama et al., 2000; Huijgbregts et al., 2000; Odorizzi et al., 2000). In particular, lipids of the phosphatidylinositol phosphate group have been recognized as important regulatory molecules, presumably mediating signals or providing points of aggregation for specific proteins (Wera et al., 2001). For the fusion machinery of the yeast vacuole it could be shown that $\mathrm{PIP}_{2}$ (phosphatidylinositol-4,5-bisphosphate) is necessary at two different stages of the fusion event (Mayer et al., 2000). Phosphatidylinositol-4-phosphate (the precursor of phosphatidylinositol-4,5-bisphosphate) is a regulatory molecule itself the intracellular pool of which affects vacuolar morphology (Foti et al., 2001). Finding Ivy1p in this context suggests the involvement of proteins with novel, non-classical lipid-binding domains. The identification of a member of the fusion machinery as a novel-type lipid-binding protein may lead to a deeper understanding of the mechanics of fusion, in particular the physical interactions of molecules necessary for removing/ attachment of proteins to/from the membrane or for stabilising/ destabilising distinct membrane regions.

\section{Materials and methods}

\section{Yeast cell growth and genetic manipulation}

Yeast strains used are described in Table I. Yeast culturing, transformation, DNA and protein extraction was done according to Adams et al. (1997). To overcome growth inhibition in galactose-containing media, $0.02 \%$ sucrose (from a sterile $20 \%$ stock solution) was added where necessary.

Yeast epitope tagging was carried out as described by De Antoni and Gallwitz (2000). Epitope-tagging modules were obtained with short flanking homolog $(\mathrm{SFH})$ primers working on the template plasmids described by De Antoni and Gallwitz (2000). Primers for IVY1-tagging
Tab. II. Plasmids generated for this study.

\begin{tabular}{ll}
\hline pTL44: & pAS2-YPT7(T22N) (Ndel-BamHI) \\
pTL68: & pAS2-YPT7 (Ndel-BamHI) \\
pTL62: & pGEX-RB-YPT7(T22N) (Ndel-BamHI) \\
pTL63: & pGEX-RB-YPT7 (Ndel-BamHI) \\
pTL78: & pEGKT-2-IVY1-HA (Xbal-HindlII) \\
pTL81: & pAS2-IVY1 (Ndel-Stul) \\
pTL82: & pACT II-VPS45 (Ncol-Xhol) \\
pTL89: & pYX212-IVY1-HA (Ncol-Sacl) \\
pTL90: & pYX213-IVY1-HA (Ncol-Sacl) \\
pTL91: & pYX242-IVY1-HA (Ncol-Sacl) \\
pTL92: & pYX243-IVY1-HA (Ncol-Sacl) \\
pTL94: & pEGKT-2-IVY1 (Xbal-HindllI) \\
pTL95: & pEGKT-2-VPS45 (BamHI-Xbal)
\end{tabular}

Restriction sites in parentheses indicate the fragments harbouring the corresponding genes that were inserted into the different plasmids.

were TL 154: 5'-GCAGCGATACGGACGGCATGCAAGACCAGTCAAGTAATATATCCCACCACCATCATCATCACGG-3' and TL 155: 5'-CCTTTTAACCGTTTTCCTATGTATATATGCAACATTTCTCCACTATAGGGAGACCGGCAGATC-3'. Genomic epitope-tagging modules for VPS33 were obtained with the primers TL 179: $5^{\prime}$ GCCGATGGCTTGATCAATGGCACAAGGATCATGAACTCTATATCTTCCCACCACCATCATCATCAC-3' and TL 180: 5'GGTTTCTACTGCTGTCAGCCTTTATTTTCAATTTTTCTTAGTCCCACTATAGGGAGACCGGCAG AT-3'. VPS45 epitope-tagging was done with TL 209: 5'-CCTCTATACTTTCAACTAAAGAATATATGGATTCTATTAGATCTGCAAAATCCCACCACCATCATCAT CAC-3' and TL 210: 5'-GGCAATAGTAAAATGTTTTATCTGCATCGAAAAAGTTATATAGATTTATGCCACTATAGGGAGACCG GCAGA T-3'.

Gene deletions were performed with SFH loxP-kanR-loxP modules according to Güldener et al. (1996). Deletion of $I V Y 1$ was achieved by SFH recombination of a loxP-kanR-loxP cassette with the following template primers: TL 145: 5'-GAAAGTAACAGGAAGAGAAATCGGATATGCCTGACAATAATACGGCGATAGGCCACTAGTGGATCTG $-3^{\prime}$ and TL 146: 5'-GAGTTACAAATTTTATATATTACTTGACTGGTCTTGCATGCCGCAGCTGAAGCTTCGTACGC-3'. After confirmation of correct target gene deletion the kanR selection marker gene was removed by inducible cre-recombinasemediated loxP recombination where desired, according to Güldener et al. (1996).

\section{Plasmid generation and cloning}

$Y P T 7$ and $Y P T 7(T 22 N)$ and $Y P T 7(Q 68 L)$ mutant alleles were cloned by PCR from genomic DNA. An Nde I restriction site including the start

Tab. I. Yeast strains used in this study.

\begin{tabular}{|c|c|c|}
\hline Strain & Genotype & Source \\
\hline $\begin{array}{l}\text { RH 270-2B } \\
\text { cl3-ABYS86 } \\
\text { Y190 }\end{array}$ & 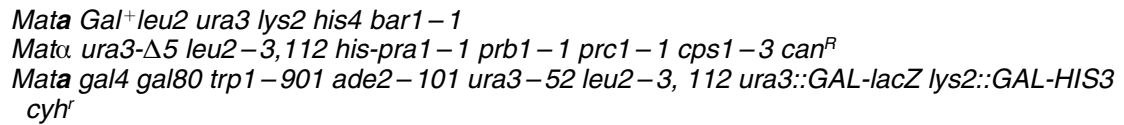 & $\begin{array}{l}\text { H. Riezman, Basel, Switzerland } \\
\text { H. D. Wolf, Stuttgart, Germany } \\
\text { S. Elledge, Houston, USA }\end{array}$ \\
\hline BHY11 & $\begin{array}{l}\text { Mata leu2-3,112 ura3-52 his3- } \Delta 200 \text { trp1- } \Delta 901 \text { ade2- } 101 \text { suc2- } \Delta 9 \text { leu2-3,112::pBHY11 } \\
\text { (CPY-InvLEU2) }\end{array}$ & B. Horazdovsky, Dallas, USA \\
\hline SEY 6211 & Mata leu2-3,112 ura3-52 his3- $\Delta 200$ trp1- $\Delta 901$ lys2 - 801 suc2- $\Delta 9$ & S. D. Emr, San Diego, USA \\
\hline TAL3 & BHY 11 ypt7:: HIS3 & This study \\
\hline TAL39 & $\mathrm{RH} 270-2 \mathrm{~B} \Delta y d r 229 w\left(k a n^{r}-\mathrm{loxP}\right)$ & This study \\
\hline TAL42 & TAL $39 \Delta k a n^{r}$ & This study \\
\hline TAL43 & BHY11 $\Delta y d r 229 w\left(k a n^{r}-\mathrm{loxP}\right)$ & This study \\
\hline TAL45 & $\mathrm{RH} 270-2 \mathrm{~B} / V Y 1-H i s_{6}-H A_{3}\left(k a n^{r}-\mathrm{loxP}\right)$ & This study \\
\hline TAL47 & $\mathrm{RH} 270-2 \mathrm{~B}$ ypt7::URA3 IVY1-His $-H A_{3}\left(k^{r} n^{r}-\mathrm{lox} \mathrm{P}\right)$ & This study \\
\hline TAL48 & TAL 42 ypt7::URA3 & This study \\
\hline TAL55 & cl-ABYS86 IVY1-His ${ }_{6}-H A_{3}\left(k a r^{r}-\mathrm{loxP}\right)$ & This study \\
\hline TAL69 & SEY 6211 vps33::URA3 IVY1-His ${ }_{6}-H A_{3}\left(k^{2}{ }^{r}-\mathrm{loxP}\right)$ & This study \\
\hline TAL88 & TAL45 VPS33-His ${ }_{6}-$ VSV $3\left(k^{r}\right.$-loxP $)$ & This study \\
\hline TAL97 & $\mathrm{RH} 270-2 \mathrm{~B}$ VPS45-His $-H A_{3}\left(k^{2} n^{r}\right.$-loxP) & This study \\
\hline TAL120 & TAL45 VPS33- - is $_{6}-V_{S} V_{3} \Delta p e p 4$ & This study \\
\hline
\end{tabular}


codon was introduced by using the oligonucleotide TL 1 (5'-CTAGAAGACATATGTTAATTTGAATTGATAC-3'). PCR fragments were subcloned into pBluescript KS II and transplanted after sequencing into two-hybrid or/and expression vectors employing restriction sites common to both plasmids. An Nco I restriction site was introduced at the 5 ' end of the coding regions of the IVY1 gene with the help of TL 167 (5'CAGGAAGAGAAATCGGCCATGGCTGACAATAATACG G-3') for cloning into the high expression vectors of the pYX series (R\&D Systems, Abingdon, UK). VPS33 expression vectors pRS325-VPS33 and pEGKT-VPS33 were kindly provided by Martin Götte. Plasmids generated for this study are described in Table II

\section{PCR}

Polymerase chain reactions were carried out in the following buffer: $10 \mathrm{mM}$ Tris- $\mathrm{HCl}, \mathrm{pH} 8.3 ; 50 \mathrm{mM} \mathrm{KCl} ; 2.5 \mathrm{mM} \mathrm{MgCl}$. The reaction mixture contained variable amounts of template DNA plus $0.2 \mathrm{mM}$ desoxy nucleoside triphosphates (dNTPs), $1 \mu \mathrm{M}$ of each primer and heat-stable polymerase. A mix of 5 parts Taq polymerase (PerkinElmer, Wellesley, MA, USA) and 1 part Deep Vent DNA polymerase (NewEnglandBiolabs, Beverly, MA, USA) was used. Genomic DNA from the EUROFAN (http://mips.gsf.de/proj/eurofan/) reference strain FY 1679 was used as template in all cases except when non-genomic DNA (e.g. plasmid DNA) was of the essence.

\section{Fusion protein production and immobilization}

Glutathione-S-transferase (GST) fusion proteins have been produced in E. coli DH5 $\alpha$ IQ (from GIBCO BRL, Invitrogen, Karlsruhe, Germany) or in the S. cerevisiae cI 3-ABYS86 strain. Induction of bacterial cultures was done with $0.1 \mathrm{mM}$ IPTG for 1 to 4 hours, depending on the protein of interest. Fusion protein expression in yeast was done by transferring cells after washing with sterile water into galactose-containing medium. Induction time of yeast cultures expressing GST-fusion proteins was $12-48$ hours, depending on the protein of interest. Harvest and purification of the fusion proteins was identical with bacterial and yeast cells and carried out as described in the manufacturer's manual (Pharmacia, Sweden). Buffer of choice for the experiments described in this article was PBS (prepared according to Sambrook et al. (1989)), supplemented with proteinase inhibitors.

\section{Overexpression of Ivy $1 p$}

To achieve strong overproduction of Ivy1p in the cell, IVY1 was cloned by PCR and inserted into pYX212, pYX213, pYX242, and pYX243 expression vectors (R\&D Systems) as an Nco I-Sac I fragment for inducible or constitutive high expression from TPI or GAL1 promoters. IVY1 was amplified by PCR on genomic FY 1679 DNA via the primers TL 167: 5'-CAGGAAGAGAAATCGGCCATGGCTGACAATAATACGG- $3^{\prime}$ (introducing an Nco I site at the ATG start site of $I V Y 1$ ) and TL 144: 5'-TCCAGCATGTTCTTGATGG-3' (a natural Sac I site some 60 base pairs upstream of TL 144 was employed to trim the PCR product for insertion). Inserts were fully sequenced to confirm error-free PCR.

\section{Lipid binding assay}

Phospholipid mixtures (various amounts of phosphatidylserine, phosphatidylinositol, phosphatidylinositolphosphates and phosphatidylinositolbisphosphates) (SIGMA) were supplemented with Rhodaminephosphatidylethanolamine (Rh-PE) $(1 \% \mathrm{w} / \mathrm{w})$ and dissolved in chloroform:methanol $(1: 1)$. The content of phospholipids was verified by HPTLC separation as previously described (Mayer et al., 2000). Phospholipid mixtures were dried under $\mathrm{N}_{2}$, resolved in $10 \mathrm{mM}$ HEPES $(\mathrm{pH} 7.4 ; 100 \mathrm{mM} \mathrm{NaCl})$, sonicated and centrifuged. Supernatants containing small unilamellar vesicles were used in binding assays with glutathione-Sepharose-immobilised proteins.

Lipid binding assays were performed as described previously (Soom et al., 2001). Immobilised GST-fusion proteins and small unilamellar vesicles $(500 \mu \mathrm{g}$ phospholipid/ml; $50 \mu \mathrm{l} / \mathrm{sample})$ were mixed in binding buffer to a total volume of $100 \mu \mathrm{l}$ and incubated with agitation at $28^{\circ} \mathrm{C}$ for $30 \mathrm{~min}$. The Sepharose was spun down, washed with binding buffer, and liposome binding to immobilised proteins was quantified by fluorescence measurement in 96-well plates (Fluoroscan II, Laborsystems $\mathrm{GmbH}$, Frankfurt, Germany) using $390 \mathrm{~nm}$ and $590 \mathrm{~nm}$, respectively, as excitation and emission wavelengths. Data presented were corrected for non-specific binding by subtracting the fluorescence found for glutathione-Sepharose alone.

\section{Cell fractionation, in vivo secretion assay and immunoprecipitation of radiolabeled CPY}

Subcellular fractionation experiments were carried out as described by Wichmann et al. (1992). Missorting of the recombinant CPY-invertase hybrid reporter protein was monitored by an invertase overlay assay according to Horazdovsky et al. (1994). Colour development was followed for up to 1 hour.

Immunoprecipitation of radiolabeled carboxypeptidase $\mathrm{Y}$ was done as described by Wichmann et al. (1992). Aliquots were taken at time 0 and 45 minutes later. Precipitates were separated on 8\% SDSpolyacrylamide gels. Exposition to X-ray films (Eastman Kodak, Rochester, NY, USA) was carried out at $-80^{\circ} \mathrm{C}$ to enhance chemical signal amplification by Amplify ${ }^{\mathrm{TM}}$ (Amersham, Berkshire, UK).

\section{Electron microscopy}

Yeast cells were grown to an optical density of $0.7-1.2($ measured at $\lambda=$ $600 \mathrm{~nm}$ ), harvested by gentle sedimentation (max. 500g) at room temperature. Aliquots of approximately $1 \mu \mathrm{l}$ were shock-frozen at $-190^{\circ} \mathrm{C}$ on the copper mirror of a Leica KF 80 cryofixation unit. For freeze-substitution the samples were transferred to $0.2 \%$ uranyl acetate in pure acetone and kept at $-85^{\circ} \mathrm{C}$ for 6 days in a Leica EM AFS cryosubstitution unit. During the next 2 days the samples were infiltrated with $\mathrm{HM} 20$ resin at $-35^{\circ} \mathrm{C}$. The resin was polymerized by UV light at $-35^{\circ} \mathrm{C}$ for 2 days and for 1 day more at $+25^{\circ} \mathrm{C}$. Ultrathin sections were contrasted with lead citrate.

\section{Results}

A two-hybrid cDNA library screen was performed to find novel proteins that physically interact with the transport GTPase Ypt7p. To select for proteins with a putative preference for the GDP-bound form of the GTPase, the mutated form Ypt7(T22N)p was used for the bait fusion with the DNAbinding part of the Gal4 protein. This bait fusion protein was tested against a yeast cDNA library (kindly provided by Bruce Horazdovsky, Dallas, USA). After a thorough analysis of the obtained two-hybrid system candidate clones, the gene YDR229w (named IVY1 for: Interacting with $V \mathrm{ps} 33 \mathrm{p}$ and $Y \mathrm{pt} 7 \mathrm{p}$ ) was singled out as the only new protein faithfully interacting with the GTP-binding protein Ypt7p. IVY1 encodes a 453-amino-acid polypeptide chain (Fig. 1).

All isolated clones harbouring this cDNA contained a $5^{\prime}$ truncated form of the gene YDR229w lacking the first 34 codons. The Saccharomyces cerevisiae genome does not contain any homologue of $I V Y 1$ or any other gene coding for a protein of any significant similarity to Ivy1p. Ivy1p therefore represents a novel protein type, hitherto unknown to interact with GTPbinding proteins of the Ras superfamily.

A computer search for homologues from other organisms has not yielded any protein with a significant degree of similarity in primary structure to Ivy1p in higher eukaryotes. However, a gene coding for a 398-amino-acid protein with sequence homology to $I V Y 1$ does exist in the fungus Neurospora crassa (accession numbers: CAD11793; emb AL 442164.1; NCB2J23; N. crassa DNA linkage group II, BAC clone B2J23). 
1 MPDNNTEQLQ GSPSSDQRLR VDWDNGNHFD VSPDRYAPHL SEFYPIVNSK RPVASSAGSE

61 NNDHLDDMNH LRSSKVYSKA RRASSITSGT STINDLQTLI TKRDVKETQE ALSTLLRNSN

121 AYSDSLLKTS QNGAEIAHSL ENIAKLKGCN DETAEKLLSA SGLFYLLSNH QLIMSKYFND

181 LLGDNLIDDI DEFELQTKIM ENKFKAQSKE QSLKLKLQER HNFDISKRKI RNLISYRESL

241 SSLQARLDQL ETLKHDFYMD SYELVENTCN KVLSKVATVS RAQVEISENI ARKGWSGGGL

301 DELLCDADDP FSKKADGPYG TIGGDGETAG EAYNSDEETG GNDVVLNELL EGTSQPSTSK

361 TSLPKSKGSS TVSTPNHSQS SSNKDGVRNN GGGKNGEDED TDNLMGTENS FSLPPTRNSA

421 EETTQTFKQL SIKEDNDNHS SDTDGMQDQS SNI

Fig. 1. Primary structure of Ivy1p (Ydr229w). The translation product of the YDR229w gene consists of 453 amino acids. The codons for the

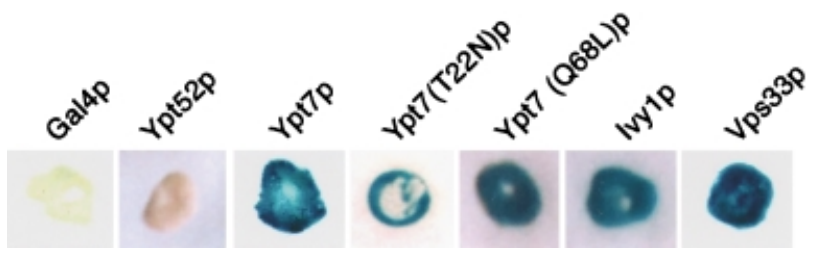

Fig. 2. Two-hybrid system interactions of Ivy1p. Ivy1p yields positive lacZ assay results with the transport GTPase Ypt7p (wild-type), the mutant GTPases Ypt7(T22N)p (predominantly in the GDP-bound form) and Ypt7(Q68L)p (predominantly in the GTP-bound form), with itself, and with Vps33p. No lac Z activation is seen with either the Gal4p activation domain or with the Gal4p DNA-binding domain when Ivy1p is fused to the corresponding second half of the Gal4 protein. Ypt52p is shown as an example of a Ypt7p-related GTPase that tests negative.

\section{Ivylp interacts with the transport GTPase Ypt7p and with the Sec1-related Vps33p}

After Ivy1p had been identified as a binding partner for Ypt7(T22N)p, the specificity of this interaction was probed by testing the new protein with a number of related GTPases from baker's yeast. Positive lacZ reactions (blue staining colonies) were seen with Ypt7(T22N)p, Ypt7p (wild-type), and GTPase acitivity-deficient Ypt7(Q68L)p (Fig. 2). A faint reaction was also seen with Ypt10p. Even if it was reproducible, it was not followed up because of the weakness of the signal. Unequivocally negative lacZ reactions were reproducibly achieved with the transport GTPases Ypt51p, Ypt52p, Ypt6p, Ypt6p(Q/ L), Ypt31p, and Sec4p. A strong, positive lacZ reaction was obtained with Ivy1p fused to both parts of the Gal4 protein: Ivy1p also interacts with itself (Fig. 2). After Ivy1p was established to interact specifically with the vacuolar transport GTPase Ypt7p, a number of specific proteins, components of the vacuolar membrane fusion machinery and respective counterparts as controls, were tested for their two-hybrid system interactions with Ivy1p. The only protein from this group which tested positive in the lacZ assay was the vacuolar Sec1-related Vps33p (Fig. 2). The endosomal Sec1 homologue Vps45p consistently tested negative. Ivy1p did not show lacZ activation in combination with the vacuolar syntaxin-like protein Vam3 (t-SNARE) in either its full-length version containing the C-terminal transmembrane domain or a truncated version lacking the transmembrane domain first 34 amino acids were missing in the retrieved two-hybrid cDNA plasmid clones.

(Vam $3 \Delta \mathrm{C}$ ). The negative lacZ assay outcome of this interaction test was borne out by testing the endosomal syntaxin-like SNARE Pep12p. Furthermore, Ivy1p did not show any interaction in the two-hybrid system with the GTPase-activating protein (GAP) for Ypt7p, Gyp7p. Gyp6p (Ypt6p-GAP), used as a control for this combination, likewise tested negatively.

\section{Affinity-chromatography experiments confirm the two-hybrid system interactions}

To confirm the consistent two-hybrid system interaction data described above, the interacting proteins were either epitopetagged and/or expressed as GST fusion proteins. Bacterially produced GST-Ypt7p, but not GST, scavenged HA-epitopetagged Ivy1p from a cleared yeast cell lysate. HA-epitopetagged Sec24p, used as a control, was not retained on a column with either GST or GST-Ypt7p. The HA epitope did not influence the outcome of this experiment. Ivy1-HAp was retained by GST-Ypt7p and by GST-Ypt7(T22N)p in comparable amounts (Fig. 3A). The specificity for the GTPase Ypt7p that had been seen in the two-hybrid system assay was confirmed by comparing the ability of Ypt7p and Ypt1p (used as control) to hold back Ivy1-HAp from a cleared yeast cell lysate (Fig. 3B). In this in vitro experiment Ivy1-HAp interacts with very similar efficiencies with both the GDP- and the GTPbound forms of Ypt7p, but not with nucleotide-loaded Ypt1p. No detectable Ivy1-HAp was found on the GST-Ypt1p matrices after extensive washing. In contrast, Ivy1-HAp binds efficiently to GST-Ypt7p, irrespective of whether the GTPase is preincubated with GDP or GTP. Only a small fraction of the bound Ivy1-HAp is released by washing buffer containing $1 \mathrm{M}$ salt. This observation is in agreement with the two-hybrid assay results that showed no visible discrimination of Ypt7p or its mutant forms by Gal4-Ivy1p.

In a direct precipitation of HA-tagged Ivy1p from yeast cells expressing GST-tagged Ypt GTPases, Ivy1-HAp was retrieved in copious amounts by GST-Ypt7p and, to a lesser degree, also by GST-Ypt6p (Fig. 3C). The relation between the signals for GST-Ypt7p and GST-Ypt6p in Figure 3C does compare roughly to the relation between Ypt7p and Ypt1p in Figure 3B. Ypt6p did not lead to a positive lac $Z$ reaction in a two-hybrid interaction assay, though. The much weaker interactions with either yeast cell-derived GST-Ypt6p and bacterially produced, 


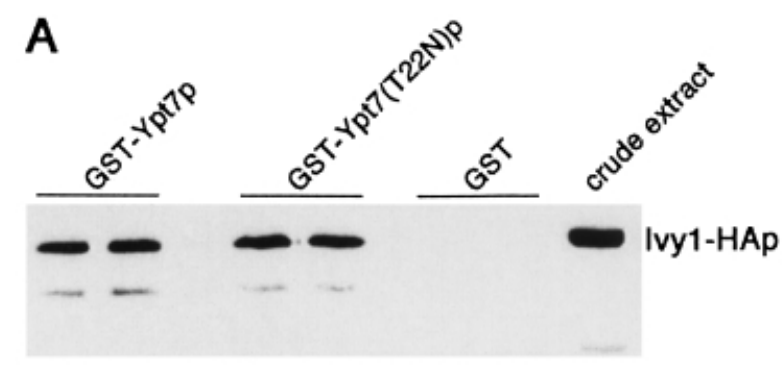

B
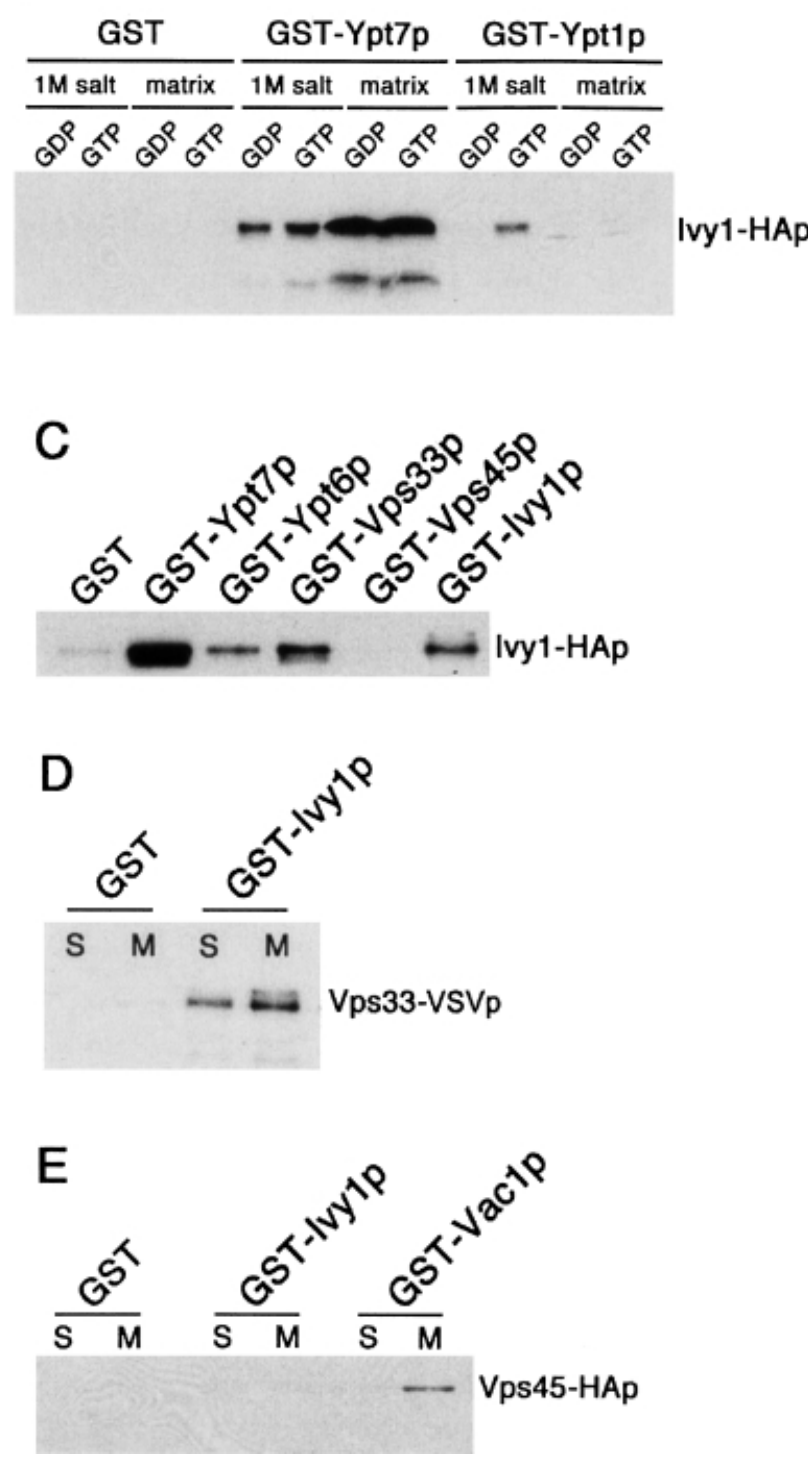

GTP-bound GST-Ypt1p (as compared to GST-Ypt7p in both Fig. 3B and Fig. 3C) are most probably not meaningful in vivo.

As attempts to produce soluble recombinant Ivy1p fusion proteins in bacteria encountered obstacles, GST-Ivy1-HAp and GST-Ivy1p were instead produced in protease-deficient yeast strains. Using this approach, we could cross-prove the interaction with Ypt7p (detected by anti-Ypt7p antisera) and with Vps33p. Vps33p, and its related endosomal counterpart, Vps45p, were tagged with either the HA or the VSV epitope
Fig. 3. In vitro protein-binding studies with Ivy1p. (A) Ivy1p (tagged with $\mathrm{C}$-terminal HA-epitopes) interacts with bacterially produced recombinant GST-Ypt7p and GST-Ypt7(T22N)p but not with unmodified GST. (B) Ivy1-HAp is retained on sepharose affinity matrices loaded with GST-Ypt7p. No detectable binding is observed on matrices containing GST only. Matrices loaded with GST-Ypt1p (an ER-Golgi transport GTPase) are able to bind minute amounts of Ivy1p when Ypt1p is activated by GTP. The portion of Ivy1-HAp bound to GTPYpt1p is released by washing with $1 \mathrm{M}$ sodium chloride solution. Equal amounts of the GST-GTPases were used for the experiment, GST was used in excess. GST and GST fusion proteins were produced in E. coli cells. (C) Affinity purification of Ivy1-HAp from yeast cells. Yeast cells containing HA-epitope-tagged Ivy1p (strain TAL 55) were transformed with plasmids allowing inducible expression of GST fusion proteins. GST fusion proteins (or GST) were purified from cell extracts and assayed for bound Ivy1-HAp by immunoblotting with anti-HA antibodies. Ivy1-HAp is found on washed Sepharose matrices containing GST-Ypt7p, GST-Vps33p and GST-Ivy1p. A small amount of Ivy1HAp (compared to GST-Ypt7p) is found attached to GST-Ypt6p. (D) VSV-tagged Vps33p binds to GST-Ivy1p but not to GST alone. GST or GST-Ivy1p were produced in yeast cells expressing Vps33-VSVp (strain TAL 120). (E) Cells containing a chromosomally HA-tagged version of the VPS45 gene (strain TAL 97) were probed with GST or GST fusion proteins. Vps45-HAp binds to Vac1p (as described by Tall et al., 1999) but not to GST or GST-Ivy1p, confirming the specificity for Vps33p of Ivy1p. $\mathbf{S}=$ Wash buffer PBS $+1 \mathrm{M}$ sodium chloride. $\mathrm{M}=$ GlutathioneSepharose matrix after high ionic strength wash/elution step with $1 \mathrm{M}$ salt. Crude extract $=$ total cell lysate cleared of cell walls. 0.5 O.D. ${ }_{600}$ units were loaded.

by modifying the chromosomal VPS33 and VPS45 genes according to De Antoni and Gallwitz (2000). By expressing GST-Ivy1p or/and various other GST-tagged proteins (detected by anti-GST antibodies) in cells containing a chromosomal copy of the IVY1-HA gene, it was possible to confirm the interactions known from the two-hybrid fusion experiments, including Ivy1p-Ivy1p self-interaction (Fig. 3C, D). GSTVps33p could retain Ivy1-HAp while GST-Vps45p could not. In a reciprocal experiment, GST-Ivy1p was able to retain epitope-tagged Vps33-VSVp (Fig. 3D) but was unable to hold back epitope-tagged Vps45-HAp (Fig. 3E). Vps45p did bind to GST-tagged Vac1p, though. Vac1p exhibits a similar set of interactions (a transport GTPase, Ypt51p, the Sec1p/Vps33prelated Vps45p, and a phosphatidylinositol-phosphate, PI-3-P) as Ivy1p (Tall et al., 1999). The specificity of the interaction for the Sec1-family member Vps33p was in this way validated, too (Fig. 3C, E).

\section{Deletion of IVYI is phenotypically neutral}

Removal of the chromosomal copy of the entire coding region of the gene $I V Y 1$ by the short flanking homology (SFH) PCR replacement method described by Güldener et al. (1996) led to an ivyl deletion strain (ivyld, TAL39/TAL42). Correct and specific removal of the $I V Y 1$ coding region was confirmed by analytical PCR and by Southern blotting (not shown). The ivyl deletion strains in any assayed way behaved exactly like wildtype yeast strains. Growth rates at temperatures from $14^{\circ} \mathrm{C}$ to $40^{\circ} \mathrm{C}$ were indistinguishable from the parent strain the deletion strains were based on. Growth on various media containing a range of additives did not differ from the parent strains. Particular attention was paid to the vacuole of $i v y 1 \Delta$ cells. Protein transport to the vacuoles (monitored by the trafficking of carboxypeptidase Y, see below) and vacuolar morphology were undisturbed and indistinguishable from wild-type yeast cells. The cells of a $y p t 7 \Delta$ ivy $1 \Delta$ double knock-out strain 


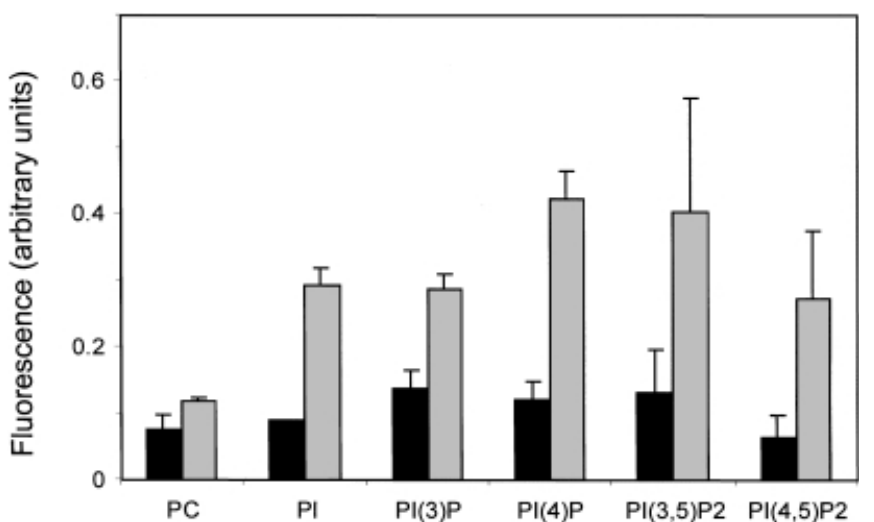

Fig. 4. Phospholipid-binding capacity of Ivy1p. Immobilized GST (black columns) or immobilized GST-Ivy1p (grey columns) (450 ng protein, respectively) were incubated with liposomes containing phosphatidylcholine (PC) and $10 \%(\mathrm{w} / \mathrm{w})$ of the phosphatidylinositol phosphates indicated, supplemented with Rhodamine-PE (1\%). Absolute fluorescence values were taken and corrected for the different $( \pm 15 \%)$ amount of Rhodamine-PE incorporated $(n=2-4$ independent experiments).

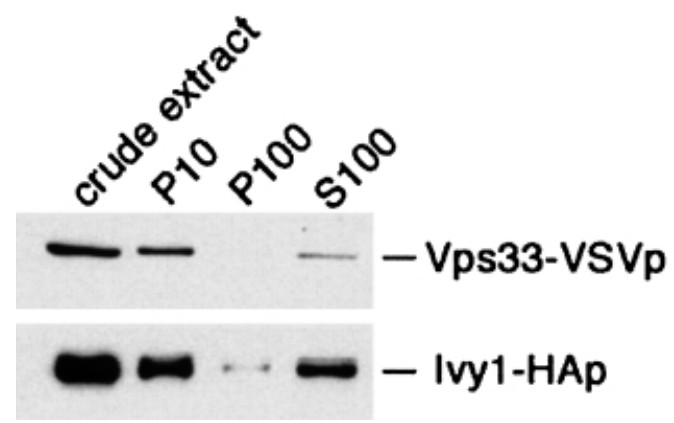

Fig. 5. Subcellular fractionation and distribution of Ivy1p and Vps33p. Yeast cells (strain TAL 120), grown to an O.D. 600 of approximately 1 , were broken in the presence of proteinase inhibitors and cleared of cell wall fragements and unbroken cells by centrifugation at $500 \mathrm{~g}$. The resulting supernatant is the crude extract, which was subjected to differential centrifugation steps at $10000 \mathrm{~g}(\mathrm{P} 10)$ and at $100000 \mathrm{~g}$ (P100). The supernatant of the $100000 \mathrm{~g}$ run (S100) contains the pool of soluble, cytosolic proteins. P10 contains membraneenclosed organelles and heavy supramolecular assemblies. Vps33p and Ivy1p were identified on protein blots by commercial antibodies directed against the respective epitope tags.

(TAL48) did not exhibit any modulation of the ypt7 single deletion. Additional deletion of IVY1 did not yield any observable synthetic effect with regard to growth, vacuolar morphology, CPY and alkaline phosphatase (ALP) transport defects.

\section{Ivylp binds phospholipids}

From the analogy with the protein Vac1p in terms of being able to bind a specific transport GTPase and its cognate Sec1 homologue, the conjecture was made that Ivy1p might exhibit further similarities with Vac1p. Vac1p is known to bind the signal lipid phosphatidylinositol-3-phosphate (Tall et al., 1999). We therefore tested whether Ivy1p can bind lipids, too. By a liposome-based capture assay (Mayer et al., 2000), we found that Ivy1p binds certain phospholipids with high affinity.
Immobilized GST-Ivy1p was incubated with liposomes containing phosphatidylcholine alone, phosphatidylcholine/phosphatidylinositol (1:1 ratio) or a mixture of phosphatidylserine and several phosphatidylinositolphosphates. Compared to immobilized GST, GST-Ivy1p showed strong binding to the phosphatidylinositide vesicles, with preference for higher phosphorylated derivatives. To further elucidate the binding specificity of Ivy1p, vesicles were constructed with a $10 \%(\mathrm{w} / \mathrm{w})$ content of distinct phosphatidylinositides in a background of phosphatidylcholine. Ivy1p bound all phospatidylinositides tested with a preference for 4-phosphorylated phosphoinositides over 3-phosphorylated phosphoinositides (Fig. 4).

\section{Ivy 1 p and Vps33p show similar distributions}

To get access to the in vivo behaviour of Ivy1p, yeast cells expressing Ivy1-HAp and Vps33-VSVp were fractionated as described by Wichmann et al. (1992). A crude extract, cleared of cell wall fragments, served as standard, representing $100 \%$ of the cellular protein. Pellets were redissolved after $10000 \mathrm{~g}(\mathrm{P} 10)$ and $100000 g$ (P100) centrifugations. The supernatant after the $100000 \mathrm{~g}$ (S 100) run is cytosol with soluble proteins. Ivy1-HAp is predominantly found in the $\mathrm{P} 10$ fraction. A minor portion of Ivy1-HAp is found in soluble form (S100 fraction), and only a minute quantity of the protein is detectable in the P100 fraction. This distribution is similar to the one for Vps33-VSVp. Ivy1p and its binding partner Vps33p behave in similar fashions in this crude fractionation experiment (Fig. 5).

\section{Localization of Ivy $1 p$}

The intracellular localization of Ivy1p was studied by indirect immunofluorescence of the epitope-tagged protein. As a reference, the localization of its interaction partner Ypt7p was used since the membrane-bound pool of this GTPase is known to localize to vacuolar membranes (Haas et al., 1995). In yeast cells of exponentially growing cultures (O.D. 600 approximately 1), no distinct subcellular distribution of the Ivy1p protein could be detected with anti-HA antisera. In cells approaching stationary phase (O.D. 600 approximately 8), a distinct fluorescence distribution at the vacuolar perimeter was found, similar to that of Ypt7p (Fig. 6A). When the expression of the HA-tagged Ivy1p protein was followed by immunoblotting, a steady increase in the amount of the protein up to a point of saturation was found in high-cell-density cultures (Fig. 6B). In exponentially growing yeast cultures, the amount per cell of Ivy1-HAp is either not sufficient for detection by indirect immunofluorescence or the protein changes its distribution when the cellular protein content rises, or newly synthesized Ivy1-HAp in stationary cells localizes to the perimeter of the vacuole.

\section{Ivy 1 p senses the absence of its binding partners}

The striking difference in electrophoretic behaviour of Ivy1p derived from wild-type versus ypt 7 mutant cells (seen in Figure 6B) led to the investigation of Ivy1p in various mutant genetic backgrounds (Fig. 7). Wild-type cells show HA-tagged Ivy1p as a pair of distinct bands migrating very close to each other (Fig. 7, best seen in vam3 mutant cells in which Ivy1p behaves as in a wild-type genetic background). A band shift towards faster migration in a denaturing SDS-polyacrylamide gel was seen in cells having no Ypt7p at all (ypt7A) or synthesising the mutated form Ypt7(T22N)p. A slight difference in mobility can be distinguished between these two mutant 


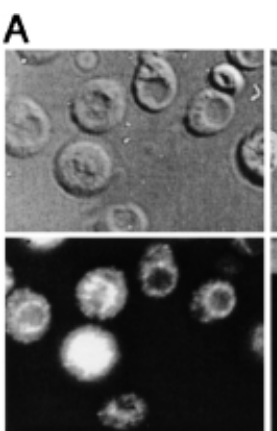

anti-Ypt7p

Antiserum

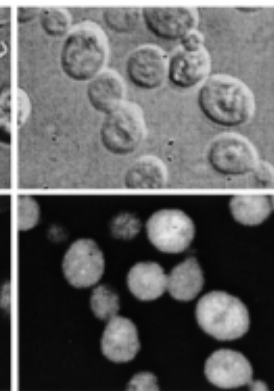

anti-HA epitope Antiserum

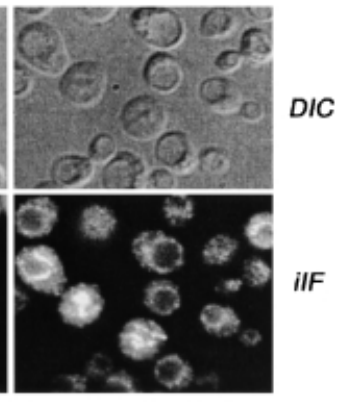

anti-HA epitope Antiserum
B

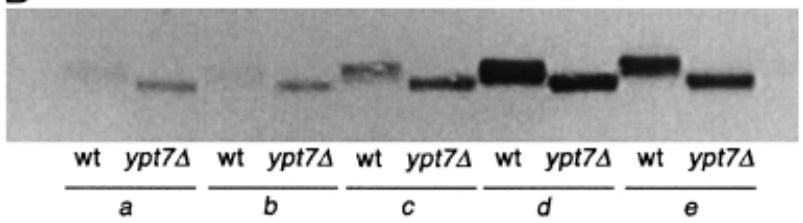

Fig. 6. Localization of Ivy1p and growth phase-dependent expression. (A) By indirect immunofluorescence, the GTPase Ypt7p was shown to localize predominantly to the vacuole (left panel). In yeast cells of exponentially growing cultures, Ivy1-HAp is not readily localizable. Only a diffuse signal all over the cell is seen (centre panel). In aged cells of stationary or near stationary cultures, Ivy1-HAp shows in indirect immunofluorescence a punctate staining at the rim of the vacuole (right panel), reminiscent of the localization of Ypt7p. (B) Aliquots of cells were drawn from a wild-type (wt) and a ypt7 $\Delta$ yeast culture at regular intervals, and the total protein normalized for the number of cells in each sample, was separated by denaturing gel electrophoresis. The amount of Ivy1-HAp increases steadily until a saturation point is reached in cells of an optical density at $600 \mathrm{~nm}$ of about 6. Samples were retrieved at an O.D. ${ }_{600}$ of about $0.15(a), 1(b), 2.5$ $(c), 5(d)$, and $8(e)$.
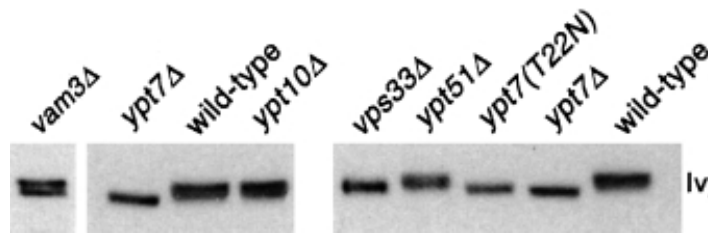

Ivy1-HAp

Fig. 7. Ivy1p senses the absence of its proteinaceous binding partners. Total protein extracts from various strains containing chromosomally HA-epitope-tagged $I V Y 1-H A$ genes were separated by SDS-PAGE. Wild-type cells (and vam $3 \Delta$, ypt51 $1 \Delta$ and ypt $10 \Delta$ deletion/disruption mutant strains) show an anti-HA antibody-reactive double band (best seen in the vam $3 \Delta$ cells). In strains which harbour a YPT7 mutant allele or which are deleted for genes encoding translation products that interact with Ivy1p, only a single, faster moving anti-HA-reactive band is seen.

cell lines, suggesting that the state of Ivy1p differs between the ypt7 null mutant and the one harbouring a functionally impaired Ypt7 protein. A band shift similar to the one in

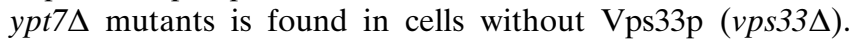
Deletion of other genes coding for Ypt GTPases has no effect

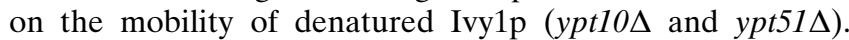
Deletion of the VAM3 gene, coding for a vacuolar SNARE protein, does not affect Ivy1p. Ivy1p specifically reacts to the presence/absence of its binding partners Vps33p and Ypt7p. In the case of Ypt7p, Ivy1p is sensitive not only to the presence or absence of the GTPase but, in addition, to either the functional status of Ypt7p (Ypt7(T22N)p is bound to GDP and inhibited in nucleotide exchange) or its overall functionality (Fig. 7). Cells expressing the preferentially GTP-bound mutant protein Ypt7(Q68L)p (which is inhibited in its GTP-hydrolytic capacity) invariably gave blurred Ivy1p bands that did not allow a statement with regard to reactivity of Ivy1p towards this mutant form. The band shift in the ypt7 $\Delta$ mutant could be remedied by adding back and expressing $Y p t 7 p$ from a plasmid (not shown). The molecular nature of the modification underlying the band shift(s) is not known. Phosphatase treatment of wild-type protein extracts did not lead to a ypt7or vps33-like change in Ivy1-HAp. Phosphorylation/dephosphorylation is therefore unlikely to be the molecular cause of this effect. Conformational change can be ruled out, too, as the alterations in electrophoretic mobility were detected on SDScontaining denaturing gels. Degradation has been ruled out as only one distinct band and no further degradation products have ever been observed in the mutant strains.

\section{Overexpression of Ivy $1 \mathrm{p}$ leads to a disruption of vacuolar mophology which can be suppressed by raising the amount of Vps33p}

When we expressed GST-Ivy1p in yeast cells, a conspicuous morphological change was seen after long induction times to maximize fusion protein yield. A majority of cells in stationary expression cultures showed fragmented vacuoles, a phenotypic trait frequently seen in yeast cells deleted for genes encoding products which play a role in vacuolar transport pathways or vacuolar inheritance (see (Götte and Lazar, 1999) for review). Therefore, yeast cells were transformed with a 2-micron multicopy plasmid containing the $I V Y 1$ coding region plus 400 base pairs $5^{\prime}$ of the start codon, most likely representing the complete native promoter. Transformed cells did not show any morphological alterations visible with a light microscope, irrespective of the growth phase of the culture. The IVYI coding region (with and without a 3 '-extension for HA epitope tags) was then cloned into 2-micron high-expression plasmids with either the constitutive triosephosphate isomerase (TPI) promoter or the inducible GAL1 promoter. Cells containing plasmids with the $I V Y 1$ gene constitutively expressing large amounts of Ivy1p (with or without HA epitopes) driven by the TPI promoter showed fragmented vacuoles (Fig. 8). The same effect could be achieved with GAL1 promoter-driven Ivy1p expression but vacuolar fragmentation was only seen after considerable times of induction (more than 24 hours). A sufficiently high amount of the protein had to be synthesized before the morphological alteration could be observed. As cells constitutively expressing large quantities of Ivy1p do not show any change in growth rates as compared to wild-type cells and cells expressing the epitope-tagged protein behaved no different from ones making the unmodified Ivy1 protein, most experiments were carried out with cells expressing Ivy1HAp protein constitutively (pTL89-transformed cells). All effects described for cells overexpressing Ivy1p were observed in the same way (indistinguishable in both appearance and extent) in cells synthesizing Ivy1-HAp. Ivy1-HAp was employed to confirm the production and measure the extent of the plasmid-driven (over)expression in addition to the normal (background) amount of Ivy1p (or Ivy1-HAp) produced by the 

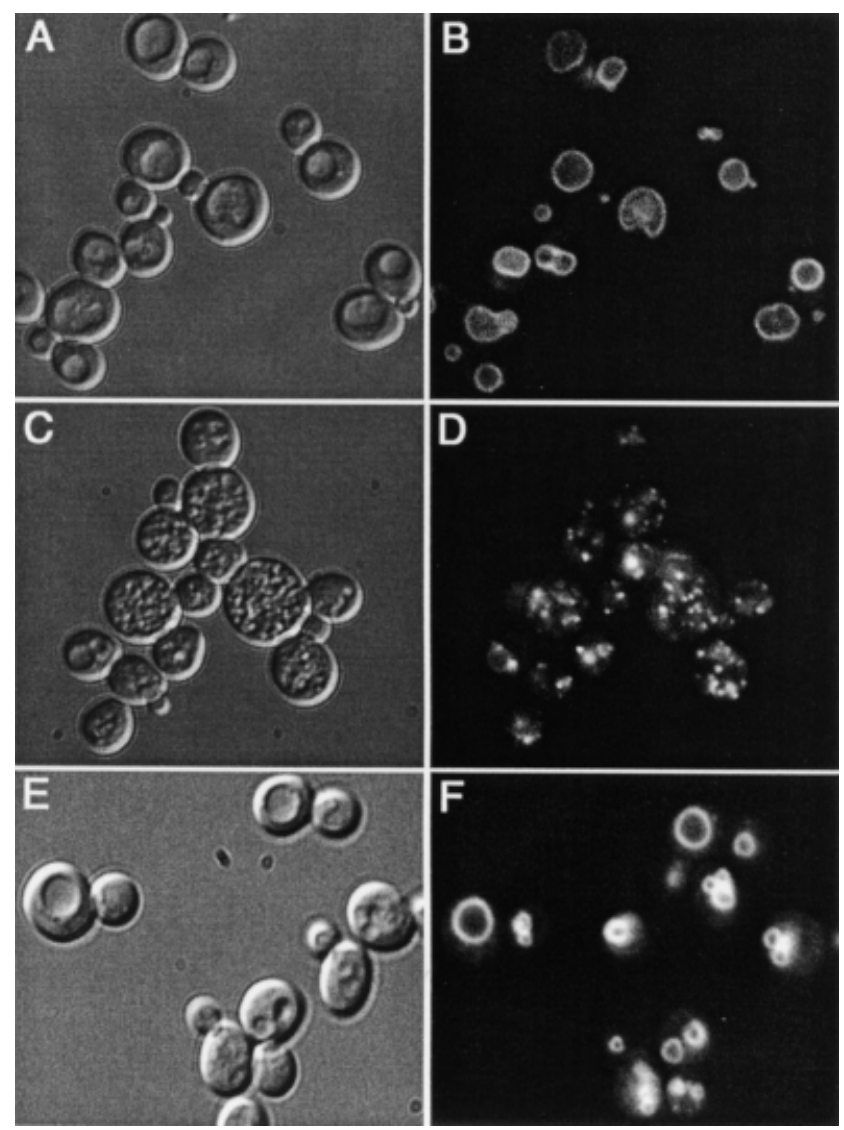

Fig. 8. Vacuoles fragment when Ivy1p is overexpressed and are restored by additional Vps33p. (A, B) Wild-type yeast cells (strain TAL 45), transformed with a plasmid to allow growth in selective drop-out medium, have normal, large vacuoles. $(\mathbf{C}, \mathbf{D})$ Cells of the same strain overexpressing Ivy1p (pTL89) show fragmented vacuoles of the $v p s$ class B mutant phenotype. (E, F) TAL 45 cells with pTL89+a $2 \mu$ multi-copy plasmid containing a wild-typeVPS33 gene show norma vacuoles. The action of the additional Vps33p counteracts the effect of Ivy1p and restores a wild-type phenotype. (A, C, E) Differential interference contrast. (B, D, F) Visualisation of vacuolar membranes with the fluorescent dye FM 4-64.

chromosomal copy of the IVY1 gene. The vacuolar fragmentation seen in yeast cells making additional Ivy1p is therefore a threshold effect for which amounts considerably above native background levels (even compared to stationary cells synthesizing larger amounts of Ivy1p habitually) are necessary.

The observation of mutant phenotype effects when Ivy1p is grossly overrepresented in the cell led to the working hypothesis that the increasing amounts of the protein seen in aging cultures might relate to the physiological role of this novel protein. To probe into the role of Ivy1p in vacuolar physiology, it was tested whether increased amounts of other proteins (namely those known to physically interact with Ivy1p) could suppress the vacuolar fragmentation in the same way plasmid-borne genes can often suppress ("rescue") phenotypes brought about by the deletion of other genes. While YPT7 was not able to set back the vacuolar breakdown, $V P S 33$ was able to neutralize the morphological change induced by Ivy1p completely when it was present on a 2micron multi-copy plasmid in addition to the chromosomal copy of the VPS33 gene. To achieve this remedial effect, it was not necessary to put VPS33 under the control of a stronger promoter. The native promoter of the gene was sufficient when additional, plasmid-borne copies were present. The suppression by heightened amounts of Vps33p of all facets of the Ivy1p overexpression phenotype was also observed independent of the fact whether the alterations were brought about by Ivy1p or Ivy1-HAp (Fig. 8).

\section{Overexpression of Ivy $1 \mathrm{p}$ leads to a massive accumulation of multivesicular bodies}

The fragmented vacuole phenotype seen by light microscopic inspection of cells overproducing Ivy1p validated ultrastructural analysis to search for additional structural alterations below the resolution threshold of the light microscope. The striking finding in cells overproducing Ivy1p was a massive accumulation of multivesicular bodies (MVBs). MVBs are believed to represent the late endosomes of eukaryotic cells (Piper and Luzio, 2001; Sachse et al., 2002), the compartment which is functionally the closest neighbour of the vacuole (lysosome). Excess amounts of Ivy1p greatly enhance the accumulation or formation of MVBs/late endosomes. The observed MVBs are of different sizes with typical diameters resembling the size of the vacuolar fragments. The MVBs do contain vesicles of various sizes but a given MVB preferentially harbours vesicles of a distinct size. A mix of vesicles differing in size was occasionally found but was not the norm (Fig. 9).

\section{Overexpression of Ivy $1 \mathrm{p}$ leads to the missorting of vacuolar proteins which can be suppressed by raising the amount of $\mathrm{Vps} 33 \mathrm{p}$}

As morphological alterations at the vacuolar level were induced by overexpression of Ivy1p rather than by deletion of the IVY1 gene, we tested whether delivery of proteins to the vacuole is also affected in Ivy1p-overexpressing cells. A missorting of vacuolar proteins is usually found to go hand in hand with changes in vacuolar morphology. Two lines of experimental evidence proved that cells strongly overexpressing Ivy1p indeed missort soluble lumenal vacuolar enzymes such as CPY.

In an enzymatic in vivo overlay assay developed by Horazdovsky et al. (1994), cells with a defect in vesicular transport to the vacuole shed into their periplasms a fusion protein consisting of the vacuolar sorting signal of CPY and the sucrose-cleaving enzyme invertase (pro-CPY-invertase). Enzyme-driven oxidation of glucose released by the secreted invertase fusion protein leads to a colour reaction if pro-CPYinvertase gets beyond the plasma membrane. A ypt7 deletion strain (TAL3; a class B vps mutant) served as standard in this assay. "Wild-type" cells of the reporter strain BHY11 were transformed with plasmids containing the $I V Y 1$ coding region under the control of either the TPI promoter (pTL89) or the inducible GAL1 promoter (pTL90). Wild-type cells with the unmodified plasmid pYX212 showed no colour development, while TAL3 ypt $7 \Delta$ cells show the expected colour reaction of a vps mutant. BHY11 cells with pTL89 show a colour reaction that is similar to that of $y p t 7 \Delta$ cells in strength and speed of the colour appearance. Cells overexpressing Ivy1p missort proteins with a vacuolar targeting signal. Reporter cells (BHY11) with pTL90 do not show any colour development when expression of the plasmid-borne $I V Y 1$ copies is not induced by galactose (Fig. 10A). 


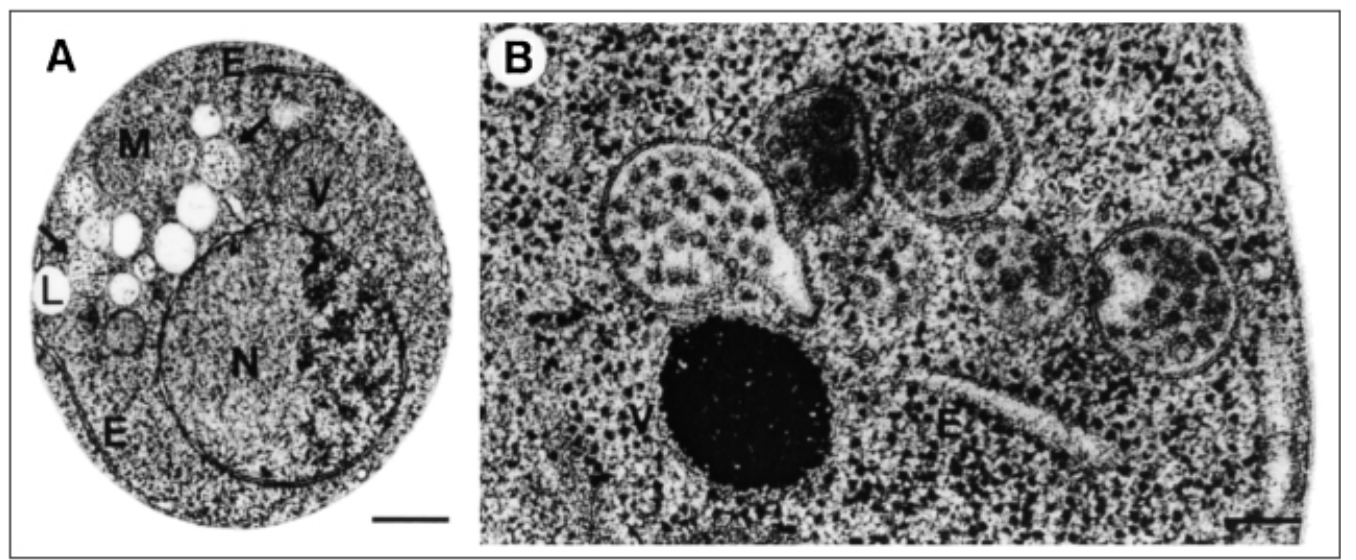

Fig. 9. Electron microscopy of yeast cells overexpressing Ivy1p. Ultra-thin sections of freeze-fixed TAL 45 yeast cells, transformed with the plasmid pTL89 exhibit unique morphological alterations at the ultrastructural level. (A) Next to remnants of the fragmented vacuolar compartment, these cells contain a vast number of multivesicular

The results obtained in the overlay colour assay were confirmed by in vivo labelling of cells with radioactive amino acids and subsequent immunoprecipitation with anti-CPY antisera (Fig. 10B). Cells strongly overexpressing Ivy1p ( + pTL89, high expression Ivy1p) show a retardation of the proteolytic processing of the portion of the reporter protein that stays inside the cell, indicating that the Golgi-derived $\mathrm{p} 2$ pro-form of CPY did not reach the vacuolar compartment where it would have been activated by partial proteolysis by proteinase $\mathrm{A}(\mathrm{Pep} 4 \mathrm{p})$. Some of the unprocessed pro-enzyme is missorted to the outside of the cell where it could be recovered by immunoprecipitation at time 0 from the medium surrounding the protoplasts used in this experiment. The (frequently observed) absence of detectable extracellular p2-pro-CPY at later times (45 minutes in this case) is most probably due to degradation of the extracellular pro-enzyme (irrespective of added proteinase inhibitors) rather than an inability of the antibodies to precipitate it (Fig. 10B). Part of the protein retained inside the cell is aberrantly processed (*, "X"-CPY; Fig. 10B; cf. (Wichmann et al., 1992)). After adding a 2-micron multi-copy plasmid containing VPS33, cells constitutively expressing Ivy1p in high amounts behave like untransformed wild-type cells (strain TAL 45). The additional Vps33 protein in these cells completely suppresses the missorting of vacuoledestined CPY in TAL $45+$ pTL89 cells (Fig. 10B). This result reflects the suppression of the vacuole fragmentation by additional VPS33 as described above (see Fig. 8).

\section{Discussion}

The gene YDR229w, named IVY1, of Saccharomyces cerevisiae codes for a protein that specifically interacts in vitro with the GTPase Ypt7p, the Vps33 protein, and, in a more promiscuous way, various phospholipids with different degrees of affinity. Both proteinaceous binding partners of Ivy1p serve important roles during the docking step of vacuolar fusion. In addition, Ivy1p has the ability to self-aggregate into either homooligomers or supramolecular structures containing multiple copies of it. bodies. (B) Multivesicular bodies (MVBs) show differing contents but individual MVBs are preferentially loaded with vesicles of equal or similar size. $\mathrm{E}=$ Endoplasmic reticulum, $\mathrm{N}=$ nucleus, $\mathrm{L}=\mathrm{Lipid}$ droplet, $\mathrm{V}=$ Vacuole, $\mathrm{M}=$ Mitochondrion, arrows point at MVBs. Scale bar: $500 \mathrm{~nm}$ in $(\mathbf{A}), 100 \mathrm{~nm}$ in $(\mathbf{B})$.

The propensity of Ivy1p to bind Ypt7p over otherYpt proteins, is strong but not perfect (cf. Fig. 3). In the living cell, the functional context in which Ivy1p exerts its effect is specified not only by its binding to Ypt7p, though, but also by other interactions. The results obtained in vitro show that binding of Ivy1p to Ypt7p may encompass structural elements common to all members of the highly related Ypt GTPase family. Physiologically meaningless interaction with Ras-like GTPases other than Ypt7p may be avoided by subcellular compartmentalization of protein distributions or by blocking of binding sites through competitive binding of other, compartment-specific factors.

Deletion of the genes for Ivy1p - interacting proteins (YPT7, $V P S 33)$ leads to strong defects in protein trafficking to the vacuole and in vacuolar morphology (cf. (Wichmann et al., 1992; Banta et al., 1990; Wada et al., 1990)). Deletion of IVY1 has proved phenotypically neutral under all conditions tested. IVY1 is dispensable for normal growth under non-competitive laboratory conditions. No protein sorting defect and no alterations in vacuolar morphology could be observed in haploid ivy1 null mutants. The absence in S. cerevisiae of any gene that shows even a weak homology to $I V Y 1$ suggests that the inconspicuousness of the $i v y 1$ deletion does not result from functional redundancy. Although its precise role in normal cellular physiology is still obscure, it can be surmised that the presence of a functional copy of the non-redundant $I V Y 1$ gene increases the fitness of the organism, although presumably in a subtle way (Thatcher et al., 1998).

In cells of exponentially growing cultures, the level of Ivy1HAp detectable with anti-HA antisera is apparently low, suggesting that in unmodified cells the Ivy1p content is equally low under these conditions. The low amount of Ivy1p in vigorously growing cells impeded detection by indirect immunofluorescence. It can therefore not be said if the low amount of protein at this stage localizes in the same way as the increased amount in stationary cells and is just below the threshold of detection, or whether Ivy1p is distributed differently in exponentially growing cells. In cultures approaching the stationary phase, the Ivy1p content of the cells rises. In the latter cells it is possible to localize the protein to the vacuolar membrane by indirect immunofluorescence. This 
A

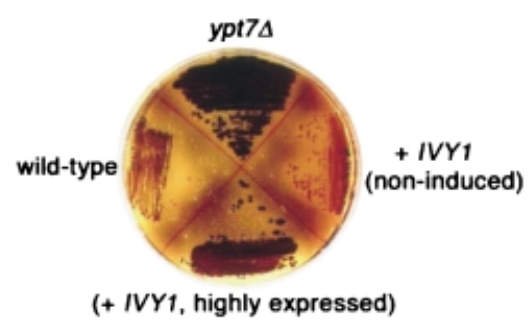

B

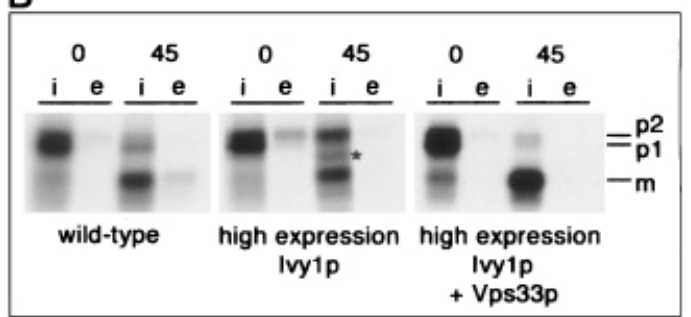

Fig. 10. Overexpression of Ivy1p leads to p2-CPY missorting. (A) In vivo overlay assay of pro-CPY-invertase secretion. ypt7 deletion cells and wild-type BHY 11 cells are used as controls. Wild-type cells (transformed with unmodified plasmids) show no colour development while ypt $7 \Delta$ cells (containing insert-free plasmids to allow growth on selective media) show a colour reaction due to misrouted pro-CPYinvertase into their periplasm. Colour develops after approximately 15 minutes due to an enzyme-catalyzed oxidation of the leuko-dye $\mathrm{O}$ dianisidine. BHY11 cells with a multi-copy plasmid constitutively synthesizing large amounts of Ivy1p (+ pTL89, bottom; IVY1 expression driven by the TPI promoter) show a colour reaction. Strong overexpression of Ivy1p leads to the missorting of soluble proteins containing a vacuolar sorting signal in their polypeptide chain. BHY 11 reporter cells containing IVYI on a multi-copy plasmid under the control of the GAL1 promoter (+ pTL90, right side) do not show any colour development when IVY1 expression is not induced. An ivyla strain (TAL43) tested by this overlay secretion assay behaved like the isogenic wild-type strain (not shown). (B) Radioactive labelling and immunoprecipitation. Cells were subjected to immunoprecipitation with anti-CPY antibodies after in vivo labeling with radioactive amino acids. After a 15 -min pulse, time 0 samples were removed and the remaining protoplasts incubated for another $45 \mathrm{~min}$. Wild-type cells show a normal processing of pro-CPY. Cells overexpressing Ivy1p (+pTL89) show a marked retention inside the cells of the p2-proform of $\mathrm{CPY}$ after $45 \mathrm{~min}$. Part of the non-matured $\mathrm{p} 2$ pro-enzyme is exported from the cell by Golgi-derived vesicles ( $\mathrm{e}=$ extracellular). This portion is seen at time 0 ; the secreted CPY at 45 min chase time was probably degraded. Additional, plamid-borne VPS33 copies inside cells overexpressing Ivy1p suppress the retarding effect on CPY maturation and restore the wild-type condition. $\mathrm{i}=$ intracellular. $\mathrm{e}=$ extracullular. $0=$ time zero, end of pulse, start of chase period. $45=$ situation after 45 minutes of chase after addition of an excess of non-radioactive cysteine/ methionine. $\mathrm{p} 1=$ core-glycosylated, endoplasmic reticulum pro-CPY; p2 = fully glycosylated, Golgi apparatus pro-CPY; $\mathrm{m}=$ matured, Pep4p-processed vacuolar CPY; * = "X"-CPY, an aberrant, presumably partially degraded, form of carboxypeptidase Y (cf. (Wichmann et al., 1992)).

localization is in agreement with its protein-protein interactions with Ypt7p and Vps33p, and it suggests that Ivy1p may have a growth phase-specific function.

While the absence of Ivy1p in $i v y 1$ deletion mutants does not lead to any detectable disadvantage, strong overexpression of the $I V Y 1$ gene leads to striking effects. Additional expression of $I V Y 1$ under control of its native promoter from a standard multi-copy plasmid did not lead to the described effects. Putting IVY1 under the control of a strong multi-copy plasmid-borne promoter such as the TPI or the (inducible) GAL1 promoter leads in transformed cells to the characteristic phenotype. Vacuolar fragmentation similar to vps class B mutants is seen. Along with this, maturation of carboxypeptidase $\mathrm{Y}$ is retarded and part of the zymogen p2-CPY is missorted to the outside of the cell. A pro-CPY-invertase fusion protein is likewise missorted to the periplasm. Overexpression of Ivy1p leads to phenotypic changes typically seen in cells deleted for VPS (vacuolar protein sorting) and/or VAM (vacuolar morphology) genes. IVY1 shows a behaviour reciprocal to the one of conventional VPS/VAM genes.

All morphological and biochemical Ivy1p overexpressionmediated effects can be completely reversed by raising the amount of Vps33p. To suppress the overexpression effects of Ivy1p, it is sufficient to provide the cells with a 2-micron multicopy plasmid harbouring the VPS33 gene in its native form. No rescue could be achieved by raising the amount of Ypt7p in the same way. From this remediation effect of Vps33p it follows that the overexpression effects seen by greatly increasing the amount of Ivy1p are threshold effects.

The idea that a certain "threshold" amount of Ivy1p needs to be present in a cell to confer the observed mutant phenotype is further supported by the fact that many but not all cells of a multi-copy transformed yeast cell culture exhibit the overexpression effects. As the cellular copy number is not precisely set in the case of 2-micron multi-copy plasmids, so that the individual plasmid copy number can vary by quite large a margin, the absence of the mutant features in some cells is explicable and, indeed, expected. The threshold theory of the Ivy $1 p$ action is supported by the observation that the overexpression effects are not seen until the liquid culture reaches a late, stationary growth phase after a shift to inducing galactose medium when $I V Y 1$ expression is driven by an inducible GAL1 promoter.

The fact that Ivy1p binds to Vps33p suggests an interpretation of the effects seen when Ivy1p is overexpressed and their perfect suppression by increased amounts of Vps33p. Vacuolar fragmentation, missorting of vacuolar proteins and the accumulation of multivesicular bodies could be due to the sequestration of the cellular Vps33p pool by the excess Ivy1p. By binding a critical portion of the cellular Vps33p, Ivy1p in this model would remove an important component of the vacuolar docking/fusion HOPS protein complex. Deletion of VPS33 leads to a vps class $\mathrm{C}$ mutant phenotype characterized by a severe fragmentation of the vacuole, missorting of pro-CPY to the periplasm and a severe growth retardation (Wada et al., 1990; Banta et al., 1990). The severity of the Ivy1p overexpression effects is more akin to vps class B mutants, though, and fragmentation of vacuoles is less pronounced than in vps $33 \Delta$ cells. Either Ivy1p does not scavenge the entire Vps33p pool, so that a residual fusion activity remains, or its action on the vacuolar fusion machinery does not affect all pathways leading to this organelle in the same way as the deletion of VPS33 does, or, most probably, the mode of action of Ivy1p contains additional levels.

This last possibility is lent support by the striking appearance of a vast number of multivesicular bodies. The generation or accumulation of multivesicular bodies inside cells overexpressing Ivy1p is a novel feature, and a massive accumulation of membrane-enclosed entities of this or a similar sort has, to our 
knowledge, never before been described in the published scientific literature on yeast cells. Multivesicular bodies (MVBs) are believed to represent a particular type of endosome in which ubiquitinated membrane proteins are delivered to the vacuole for degradation. MVBs are thought to form by invagination of endosomal membranes which pinch off to yield the vesicles found inside multivesicular bodies (Reggiori and Pelham, 2001). The massive accumulation of these organelles in yeast cells overproducing Ivy1p suggests that Ivy1p either interferes with endosome-vacuole fusion in a particular way (as MVB accumulation is not seen in vps/vam mutants in which vacuolar fusion is disabled or severely inhibited - or has escaped attention), or Ivy1p serves a role in an as yet undefined, novel pathway involving MVB-vacuole fusion. Both the vps and vam mutant phenotypes in cells with enlarged amounts of Ivy1p can successfully be suppressed when the cellular content of Vps33p is enhanced at the same time. Ivy1p and Vps33p are, at least to some degree, functionally reciprocal.

Phospholipids of the phosphoinositide group have only recently been found to be important regulatory substances of membrane fusions. As Ivy1p strongly binds to members of this group of lipids, it could be responsive to phosphoinositol-4,5bisphosphate, which Ivy1p is likely to meet at the vacuolar membrane, and which Mayer et al. (2000) have found to be important in two chronologically distinct steps of vacuolar membrane fusions. It is this lipid that in vitro shows the highest affinity for Ivy1p (Fig. 4). It is possible that the Ivy1p-lipid interaction facilitates membrane interaction in the first place which is then followed by interaction with Ypt7p and Vps33p. We cannot exclude that Ivy1p in addition reacts to another, not yet defined, lipid signal. It is intriguing, though, that the GTPases Cdc42p and Rho1p are required for vacuolar fusion downstream of Ypt7p (Müller et al., 2001; Eitzen et al., 2001). Cdc42p had previously been shown to bind directly to PI-4,5bisphosphate (Zheng et al. 1996). In addition, phosphoinositide lipids have been found to bind to guanine nucleotide exchange factors (GEFs) and GTPase-activating proteins (GAPs) via interaction with the PH (pleckstrin homology) domain found in these proteins (Welch et al., 2002; Krugmann et al., 2002; Han et al., 1998). Rho1p is activated by the PH domain-containing GEF Rom $2 p$ in a Ypt7p-dependent way (Wickner, 2002). The vacuolar fragmentation seen upon overexpression of Ivy1p could therefore be the result of its lipid-binding capacity. Excess amounts of Ivy1p could be envisaged to sequester the vacuolar PI-4,5-bisphosphate, inhibiting the action of Cdc42p and/or Rom $2 p$ by stripping them of their regulatory lipid. PI-4,5-bisphosphate was shown by Zheng and colleagues (1996) to activate Cdc42p directly through the stimulation of GDP release. It is not known if other Ras-related GTPases such as Ypt7p can be activated in the same way. In addition, a detailed picture of the interactions at the cellular membrane of mammalian $\mathrm{Cdc} 42$ bound to its guanine nucleotide exchange factor Dbs, including PI-4,5bisphosphate, has recently been described (Rossman et al., 2002), suggesting an allosteric function for the phosphoinositide in the GTPase-GEF interaction. From this working hypothesis a model for the physiological role of Ivy1p can be derived: if Pi-4,5-bisphosphate were rate-limiting for the progression of vacuolar membrane fusion, the increasing amounts of Ivy1p in aging cells could serve a regulatory role in fine-tuning or shutting down delivery of vesicular carriers/ late endosomes to the vacuole in non-dividing, stationary yeast cells. Many of the Ypt GTPases are still devoid of described proteinaceous activating factors, i.e. guanine-nucleotide exchange factors. Maybe lipids - alone or as co-factors of proteins - fulfill this function for some of the Ypt proteins. The presumptive GEF for Ypt7p, Vps39p (a member of HOPS), in vitro displays a rather low activity towards its cognate GTPase (Wurmser et al., 2000). Maybe its activity in vivo is enhanced by additional interactions with other proteins or/and lipids.

This model is able to explain the effects seen when Ivy1p is overexpressed. How increasing the amount of Vps33p (part of the Ypt7p-binding HOPS complex) facilitates the relieve of the detrimental effects of excess Ivy1p is mechanistically not fully understood at the moment. Maybe Vps33p contributes to the action of Rom $2 p$, thereby short-circuiting the need for phospholipids. Despite the severity of the respective deletionstrain phenotype ( $v p s$, class $\mathrm{C}$ ), the role of $\mathrm{Vps} 33 \mathrm{p}$ in the HOPS complex is still poorly understood.

In addition to the interactions described in this publication, Ivy1p has been found in two-hybrid system studies to interact physically with a number of yeast proteins other than the ones described here. The interactions are listed at the internet site: http://www.proteome.com/databases/YPD/reports/YDR229 W.html. To our knowledge the physiological relevance of these interactions has not been confirmed. The possibility cannot be ruled out that some of these interactions may be artifactual. Ivy1p is said to interact with: Rvs167p (Ydr388w, a protein which seems to be involved in endocytic vesicle trafficking (Bon et al., 2000)); Crm1p (Ygr218w; Exportin); Ygl066p (function unknown); Yj1017p (function unknown); Cod2p (Ynl041C; a component of the Sec34p-Sec35p complex involved in vesicular transport to the Golgi apparatus). Except for Rvs167p, all of these interactions were found in highthroughput two-hybrid screens, an experimental approach the "in-vivo validity" of which has to be borne out through confirmatory studies. The interaction of Ivy1 $p$ with the protein Rvs167p in the two-hybrid system as described by Bon et al. (2000), could be confirmed by us. In an affinity chromatographic experiment HA-tagged Rvs167p was retained by GSTIvy1p (not shown). If this interaction is of relevance in the living cell has to be determined.

In summary, our results suggest a role for Ivy1p in the vacuolar fusion machinery of the yeast cell as a antagonist for Vps33p. In this way it might add an additional level of regulation to the HOPS-controlled docking step of vacuolar membrane fusion.

Acknowledgements. The authors wish to express their gratitude to the following people: Rita Schmitz-Salue for high-quality technical assistance throughout the project, Hans-Heinrich Trepte for his excellent electron microscopy, Peter Mienkus and Ursula Welscher-Altschäffel for additional technical assistance at certain stages of the project, Bruce Horazdovsky for providing the Saccharomyces cerevisiae two-hybrid library, Martin Götte for providing various plasmids, Hans-Dieter Schmitt, Anna de Antoni, and Uwe Andag for valuable advice. This work was supported in part by grants to D. Gallwitz from the Deutsche Forschungsgemeinschaft, Fonds der Chemischen Industrie and the Human Frontier Science Program (HFSP).

\section{References}

Adams, A., Gollschling, D. E., Kaiser, C. A., Stearns, T. (1997): Methods in Yeast Genetics. Cold Spring Harbor Laboratory Press, Cold Spring Harbor, NY. 
Banta, L. M., Vida, T. A., Herman, P. K., Emr, S. D. (1990): Characterization of yeast $\mathrm{Vps} 33 \mathrm{p}$, a protein required for vacuolar protein sorting and vacuole biogenesis. Mol. Cell. Biol. 10, 4638-4649.

Bon, E., Recordon-Navarro, P., Durrens, P., Iwase, M., Toh-e, A. A., Aigle, M. (2000): A network of proteins around Rvs167p and Rvs161p, two proteins related to the yeast actin cytoskeleton. Yeast 16, 1229-1241.

De Antoni, A., Gallwitz, D. (2000): A novel multi-purpose cassette for repeated integrative epitope-tagging of genes in Saccharomyces cerevisiae. Gene 246, 179-185.

Eitzen, G., Thorngren, N., Wickner, W. (2001): Rho1p and Cdc42p act after Ypt7p to regulate vacuole docking. EMBO J. 20, 5650-5656.

Foti, M., Audhya, A., Emr, S. D. (2001): Sac1 lipid phosphatase and Stt4 phosphatidylinositol-4-kinase regulate a pool of phosphatidylinositol-4-phosphate that functions in the control of the actin cytoskeleton and vacuole morphology. Mol. Biol. Cell 12, 2396-2411.

Gerhardt, B., Kordas, T. J., Thompson, C. M., Patel, P., Vida, T. (1998) The vesicle transport protein Vps33p is an ATP-binding protein that localizes to the cytosol in an energy-dependent manner. J. Biol. Chem. 273, 15818-15829.

Götte, M., Lazar, T. (1999): The ins and outs of vacuolar trafficking. Protoplasma 209, 9-18.

Güldener, U., Heck, S., Fielder, T., Beinhauer, J., Hegemann, J. H. (1996): A new efficient gene disruption cassette for repeated use in budding yeast. Nucleic Acids Res. 24, 2519-2524.

Haas, A., Scheglmann, D., Lazar, T., Gallwitz, D., Wickner, W. (1995): The GTPase Ypt7p of Saccharomyces cerevisiae is required on both partner vacuoles for the homotypic fusion step in vacuole inheritance. EMBO J. 14, 5258 - 5270.

Hama, H., Takemoto, J. Y., DeWald, D. G. (2000): Analysis of phosphoinositides in protein trafficking. Methods 20, 465-473.

Han, J., Luby-Phelp, K., Das, B., Shu, X., Xia, Y., Mosteller, R. D. Krishna, U. M., Falck, J. R., White, M. A., Broek, D. (1998): Role of substrates and products of PI-3-kinase in regulating activation of Rac-related guanosine triphosphatases by Vav. Science 279, 558 560.

Horazdovsky, B. F., Busch G. R., Emr S. D. (1994): VPS21 encodes a rab5-like GTP binding protein that is required for the sorting of yeast vacuolar proteins. EMBO J. 13, 1297-1309.

Huijgbregts, R. P. H., Topalof, L., Bankaitis, V. A. (2000): Lipid metabolism and regulation of membrane trafficking. Traffic $\mathbf{1}$, $195-202$.

Krugmann S., Anderson K. E., Ridley S. H., Risso N., McGregor A., Coadwell J., Davidson K., Eguinoa A., Ellson C. D., Lipp P., Manifava M., Ktistakis N., Painter G., Thuring J. W., Cooper M. A., Lim Z. Y., Holmes A. B., Dove S. K., Michell R. H., Grewal A., Nazarian A., Erdjument-Bromage H., Tempst P., Stephens L. R. Hawkins P. T. (2002): Identification of ARAP3, a novel PI3K effector regulating both Arf and Rho GTPases, by selective capture on phosphoinositide affinity matrices. Mol. Cell 9, 95-108.

Kucharczyk, R., Kierzek, A. M., Slonimski, P. P., Rytka, J. (2001): The Ccz1 protein interacts with Ypt7 GTPase during fusion of multiple transport intermediates with the vacuole in S. cerevisiae. J. Cell Sci. 114, $3137-3145$.

Lazar, T., Götte, M., Gallwitz, D. (1997): Vesicular transport: how many Ypt/Rab-GTPases make a eukaryotic cell? Trends Biochem. Sci. 22 $468-472$.

Mayer, A. (2001): What drives membrane fusion in eukaryotes? Trends Biochem. Sci. 26, 717-723.

Mayer, A., Scheglmann, D., Dove, S., Glatz, A., Wickner, W., Haas, A. (2000): Phosphatidylinositol-4,5-bisphosphate regulates two steps of homotypic vacuole fusion. Mol. Biol. Cell 11, 807-817.

Müller, O., Johnson, D. I., Mayer, A. (2001): Cdc42p functions at the docking stage of yeast vacuole membrane fusion. EMBO J. 20, $5657-$ 5665.
Odorizzi, G., Babst, M., Emr S. D. (2000): Phosphoinositide signaling and the regulation of membrane trafficking in yeast. Trends Biochem. Sci. 25, 229-235.

Piper, R. C., Luzio, J. P. (2001): Late endosomes: sorting and partitioning in multivesicular bodies. Traffic 2, 612-621.

Price, A., Seals, D., Wickner, W., Ungermann, C. (2000): The docking stage of yeast vacuole fusion requires the transfer of proteins from a cis-SNARE complex to a Rab/Ypt protein. J. Cell Biol. 148, 1231 1238.

Reggiori, F., Pelham, H. R. B. (2001): Sorting of proteins into multivesicular bodies: ubiquitin-dependent and -independent targeting. EMBO J. 20, 5176-5186.

Rossman, K. L., Worthylake, D. K., Snyder, J. T., Siderovski, D. P. Campbell, S. L., Sondek, J. (2002): A crystallographic view of interactions between Dbs and Cdc42: PH domain-assisted guanine nucleotide exchange. EMBO J. 21, 1315-1326.

Sachse, M., Ramm, G., Strous, G., Klumpermann, J. (2002): Endosomes: multi-purpose designs for integrating housekeeping and specialized tasks. Histochem. Cell. Biol. 117, 91-104.

Sambrook, J., Fritsch, E. F, Maniatis, T. (1989): Molecular Cloning, vols. $1-3$. Second Edition. Cold Spring Harbor Laboratory Press, Cold Spring Harbor, NY.

Sato, T. K., Rehling, P., Peterson, M. R., Emr. S. D. (2000): Class C Vps protein complex regulates vacuolar SNARE pairing and is required for vesicle docking/fusion. Mol. Cell 6, 661 -671.

Seals, D. F., Eitzen, G., Margolis, N., Wickner, W. T., Price, A. (2000): A $\mathrm{Ypt} / \mathrm{Rab}$ effector complex containing the Sec1 homolog Vps33p is required for homotypic vacuole fusion. Proc. Natl. Acad. Sci. USA 97, $9402-9407$.

Soom, M., Schönherr, R., Kubo, Y., Kirsch, C., Klinger, R. Heinemann, S. H. (2001): Multiple PIP2 binding sites in Kir2.1 inwardly rectifying potassium channels. FEBS Lett. 490, 49-53.

Tall, G. G., Hama, H., DeWald, D. B., Horazdovsky, B. F. (1999): The PI3-phosphate binding protein Vac1p interacts with a Rab GTPase and a Sec1p homologue to facilitate vesicle-mediated vacuolar protein sorting. Mol. Biol. Cell 10, 1873-1889.

Thatcher, J. W., Shaw, J. M., Dickinson, W. J. (1998): Marginal fitness contributions of non-essential genes in yeast. Proc. Natl. Acad. Sci. USA 95, 253-257.

Wada,. Y., Kitamoto, K., Kanbe, T., Tanaka, K., Anraku, Y. (1990): The SLP1 gene of Saccharomyces cerevisiae is essential for vacuolar morphogenesis and function. Mol. Cell. Biol. 10, 2214-2223.

Welch, H. C. E., Coadwell, W. J., Ellison, C. D., Ferguson, G. J., Andrews, S. R., Erdjument-Bromage, H., Tempst, P., Hawkins, P. T. Stephens, L. R. (2002): P-Rex1, a PtdIns(3,4,5)P3- and G $\beta \gamma$ regulated guanine-nucleotide exchange factor for Rac. Cell 108, 809-821.

Wera, S., Bergsma, J. C. T., Thevelein, J. M. (2001): Phosphoinositides in yeast: genetically tractable signalling. FEMS Yeast Res. 1406, $1-5$.

Wichmann, H., Hengst, L., Gallwitz, D. (1992): Endocytosis in yeast: Evidence for the involvement of a small GTP-binding protein (Ypt7p). Cell 71, 1131-1142.

Wickner, W. (2002): Yeast vacuoles and membrane fusion pathways. EMBO J. 21, $1241-1247$.

Wurmser, A. E., Sato, T. K., Emr, S. D. (2000): New component of the vacuolar class C-Vps complex couples nucleotide exchange on the Ypt7 GTPase to SNARE-dependent docking and fusion. J. Cell Biol. 151, 551-562.

Zheng, Y., Glaven, J. A., Wu, W. J., Cerione, R. A. (1996): Phosphatidylinositol 4,5-bisphosphate provides an alternative to guanine nucleotide exchange factors by stimulating the dissociation of GDP from Cdc42Hs. J. Biol. Chem. 271, 23815-23819. 